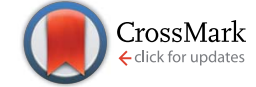

Cite this: RSC Adv., 2017, 7, 9079

Received 29th November 2016 Accepted 17th January 2017

DOI: 10.1039/c6ra27530c

rsc.li/rsc-advances

\section{Magnetic graphene oxide modified by chloride imidazole ionic liquid for the high-efficiency adsorption of anionic dyes $\dagger$}

\begin{abstract}
Huan Wang ${ }^{\mathrm{ab}}$ and Yinmao Wei ${ }^{* a}$
Magnetic graphene oxide modified with 1-amine-3-methyl imidazole chloride ionic liquid (LI-MGO) was prepared through chemical co-precipitation and modified using 1-amine-3-imidazolium chloride ionic liquid. The as-prepared LI-MGO was characterized using X-ray diffraction (XRD), transmission electron microscopy (TEM) and Fourier transform infrared spectrometry (FT-IR). The adsorption properties were evaluated through adsorption experiments with two kinds of anionic dyes, orange IV (OIV) and glenn black R (GR) and two kinds of cationic dyes, acridine orange (AO) and crystal violet (CV). The results indicated that the adsorption data fitted the Langmuir isotherm and followed pseudo-second-order kinetics. The maximum adsorption capacities for GR, OIV, AO and CV were 588.24, 57.37, 132.80 and $69.44 \mathrm{mg} \mathrm{g}^{-1}$ at $298 \mathrm{~K}$, respectively. LI-MGO has better selective adsorption for anionic dyes than magnetic graphene oxide (MGO) due to electrostatic interactions. Moreover, the LI-MGO adsorbent can be magnetic separated and is easy to prepare. It demonstrated that LI-MGO would have great potential as an efficient environmentally friendly adsorbent for the removal of anionic dyes in water treatment.
\end{abstract}

\section{Introduction}

Organic dye wastewater discharged from industrial coloring and printing processes has many detrimental effects on the environment and human health. ${ }^{1}$ With better awareness of these problems, a number of techniques to remove dyes have been employed to treat wastewater, including degradation, ${ }^{2}$ electrochemical treatment, ${ }^{3}$ reverse osmosis, ${ }^{4}$ ion exchange, and adsorption..$^{5,6}$ Among these methods, adsorption is believed to be the most effective way to remove dye from wastewater. ${ }^{7}$ Various adsorbents have been reported to remove dye from wastewater in the literature, such as clay minerals, ${ }^{8}$ oxides, ${ }^{9}$ zeolites $^{10}$ and carbon materials. ${ }^{11,12}$ However, the performance of these materials is limited by their relatively low densities of surface functional groups. ${ }^{13}$ Graphene oxide, as a kind of carbon material, has attracted much attention as a potential adsorbent due to its high specific surface area and its ease of surface functionalization, ${ }^{14,15}$ which contains a large number of carboxyl, ketone, epoxy and hydroxyl groups on its surface. ${ }^{16}$ However, graphene oxide is usually collected through high-

${ }^{a}$ Key Laboratory of Synthetic and Natural Function Molecule Chemistry of Ministry of Education, College of Chemistry \& Materials Science, Northwest University, Xi'an 710069, China. E-mail: ymwei@nwu.edu.cn; Fax: +86-29-88302604; Tel: +86-2988302604

${ }^{b}$ College of Chemistry and Chemical Engineering, Xianyang Normal College, Xianyang 712000, China

$\dagger$ Electronic supplementary information (ESI) available. See DOI: $10.1039 / \mathrm{c} 6 \mathrm{ra} 27530 \mathrm{c}$ speed centrifugation, which increases the operational cost for its practical application. ${ }^{17}$ To overcome the challenges of its difficulty of separation, $\mathrm{Fe}_{3} \mathrm{O}_{4}$ magnetic nanoparticles have been increasingly utilized in magnetic separation, due to their distinguished magnetic properties. ${ }^{18,19}$

Recently, graphene oxide ${ }^{20}$ and its hybrids were successfully synthesized with $\beta$-cyclodextrin and acrylic acid, ${ }^{21,22}$ metal oxides, ${ }^{23,24} 4$-aminothiophenol and 3-aminopropyltriethoxysilane, ${ }^{25}$ and tripolyphosphate ${ }^{26}$ to remove cationic dyes in wastewater, and showed enhanced adsorption properties because they combine the advantages of graphene oxide and functional groups. However, Ramesha et al. ${ }^{27}$ reported that graphene oxide showed removal efficiencies of up to $95 \%$ for cationic dyes, while the adsorption of anionic dyes was negligible, because the large negative charge density available in aqueous solutions helps the effective adsorption of cationic dyes on graphene oxide. Adsorbents for anionic dyes are usually surface cationic modified materials such as cationic surfactant hexadecylpyridinium bromide modified peanut shell, ${ }^{28}$ surfactant modified coir pith, ${ }^{29}$ cationic surfactant modified wheat straw, ${ }^{30}$ cationically modified orange peel powder ${ }^{31}$ and quaternary ammonium salt modified chitosan magnetic composites. ${ }^{32}$ But the adsorption capacity for anionic dyes on these adsorbents is lower. So there is an urgent need for the design of novel functional adsorbents for the efficient adsorption of anionic dyes. Changing the surface charge of graphene oxide through chemical modification is an important way to improve the effective adsorption of anionic dyes.

As a potential environmentally-friendly solvent, room temperature ionic liquids (ILs) are receiving much attention 
owing to their numerous advantages over conventional solvents, such as their good dissolving ability, recyclability, low volatility, non-flammability, high thermal and chemical stabilities, and high ionic conductivity. ${ }^{33,34}$ They have also been successfully applied in the areas of the separation of 2-phenylethanol, ${ }^{35}$ gas separation, ${ }^{36}$ and the recoveries of solvents ${ }^{37}$ and electrolytes in sensitized solar cells. ${ }^{38}$ Chen et al. ${ }^{39}$ has immobilized ammonium ionic liquids on LDHs to improve the adsorption properties for reactive orange 5 . Liu et al. ${ }^{40}$ reported that a hyperbranched polymeric ionic liquid $\left(\mathrm{hb}-\mathrm{PIm}^{+} \mathrm{PF}^{6-}\right)$ with imidazolium backbones has been synthesized and it exhibited high adsorption capacity toward anionic dyes. An imidazolium-salt based IL containing nitrogen atoms can facilitate a high atomic percentage of nitrogen as a functional solvent due to the presence of more nitrogen atoms, which can further change the surface charge of the material.

Herein, novel LI-MGO nanocomposites were designed directly from MGO and chloride imidazole ionic liquid. In this paper, we introduced $\mathrm{Fe}_{3} \mathrm{O}_{4}$ nanoparticles to synthesize MGO through chemical co-precipitation, and then we utilized a chloride imidazole ionic liquid as a functional solvent to modify MGO, to prepare MGO-IL. The introduction of the $\mathrm{Fe}_{3} \mathrm{O}_{4}$ nanoparticles could well solve the difficulty of separation, and the IL not only increased the water-solubility of the composite but also could change the functional groups on the surface of MGO. MGO and LI-MGO were used for the adsorption of two anionic dyes and two cationic dyes from simulated wastewater with fast magnetic separation. The effects of treatment time, initial concentration and $\mathrm{pH}$ value on the dye adsorption capacity of the prepared LI-MGO are investigated. The adsorption kinetics and adsorption isotherms are also investigated by fitting the experimental data with different models and an adsorption mechanism is proposed. LI-MGO is found to possess a unique capability to remove anionic dyes very quickly and efficiently from wastewater.

\section{Experimental section}

\subsection{Experimental reagents}

Flake graphite (99.95\%) was supplied by Qingdao Chenyang Graphite Co., Ltd. (Qingdao, China). Ferric chloride hexahydrate and ferrous chloride tetrahydrate were purchased from the National Medicine Group Chemical Reagent Co., Ltd. (Shanghai, China). Acridine orange (AO), crystal violet (CV), orange IV (OIV), glenn black R (GR), 1-methylimidazole and 1-amino-3-chloropropane hydrochloride were purchased from the Aladdin Chemical Reagent Co., Ltd. (Shanghai, China). The other reagents were of analytical grade.

\subsection{Preparation of adsorbents}

2.2.1 Synthesis of 1-amine-3-methyl imidazole chloride. 1Amine-3-methyl imidazole chloride was prepared according to a process reported in the literature. ${ }^{41} 35.9690 \mathrm{~g}$ of 1-methylimidazole $(0.4381 \mathrm{~mol})$ and $59.9630 \mathrm{~g}$ of 1-amino-3chloropropane hydrochloride $(0.4381 \mathrm{~mol})$ were added to a 250 $\mathrm{mL}$ three-necked flask and dispersed in $50 \mathrm{~mL}$ of anhydrous methanol. The mixture was stirred at $80{ }^{\circ} \mathrm{C}$ for $48 \mathrm{~h}$. The reaction mixture was evaporated to remove any methanol after cooling to room temperature. A white solid was obtained after placing in a refrigerator for $12 \mathrm{~h}$, and then the supernatant was poured out. The white solid was washed three times with anhydrous alcohol, which was filtered and evaporated to remove any ethanol. Then a potassium hydroxide methanol solution was added to the obtained white solid dissolved in methanol, and the $\mathrm{pH}$ was adjusted to 8.0, and this was evaporated to remove the ethanol and water. The product was dissolved in methanol, filtered to remove any potassium chloride and evaporated to remove any methanol again. Finally, the product was dried in a vacuum oven at $60{ }^{\circ} \mathrm{C}$ to obtain 1-amine-3-methyl imidazole chloride (LI).

2.2.2 Preparation of LI-GO. GO was prepared from flake graphite powder using a modified Hummers-Offeman method $^{42}$ and was then used as a starting material for the functionalization of GO. Firstly, $0.2 \mathrm{~g}$ of GO was added to $85 \mathrm{~mL}$ of thionyl chloride in a $250 \mathrm{~mL}$ three-necked flask and the mixture was ultrasonicated for $30 \mathrm{~min}$ to exfoliate the GO sheets. Then $4 \mathrm{~mL}$ of $N, N$-dimethylformamide was added as catalyst and the mixture was refluxed at $70{ }^{\circ} \mathrm{C}$ for $8 \mathrm{~h}$. Finally, the product was filtered and washed with deionized water. Then the product was dried in a vacuum oven at $60{ }^{\circ} \mathrm{C}$. The acyl chloride graphite obtained and $0.4 \mathrm{~mL}$ of $\mathrm{LI}$ was added to 100 $\mathrm{mL}$ of $N, N$-dimethylformamide and the mixture was refluxed at $80{ }^{\circ} \mathrm{C}$ for $31 \mathrm{~h}$. The product was filtered and washed with deionized water, and then the product was dried in a vacuum oven at $60{ }^{\circ} \mathrm{C}$ to obtain 1-amine-3-methyl imidazole chloridefunctionalized GO (LI-GO).

2.2.3 Preparation of MGO and LI-MGO. LI-MGO was obtained through the co-precipitation method with LI-GO and $\mathrm{Fe}^{3+}\left(\mathrm{FeCl}_{3} \cdot 6 \mathrm{H}_{2} \mathrm{O}\right)$ and $\mathrm{Fe}^{2+}\left(\mathrm{FeCl}_{2} \cdot 4 \mathrm{H}_{2} \mathrm{O}\right)$ salts in an alkaline medium. Briefly, $2.3245 \mathrm{~g}$ of $\mathrm{FeCl}_{3} \cdot 6 \mathrm{H}_{2} \mathrm{O}$ and $0.8549 \mathrm{~g}$ of $\mathrm{FeCl}_{2} \cdot 4 \mathrm{H}_{2} \mathrm{O}$ were dissolved in $30 \mathrm{~mL}$ of distilled water, which was purged under a $\mathrm{N}_{2}$ flow $\left(30 \mathrm{~mL} \mathrm{~min}^{-1}\right)$ for $30 \mathrm{~min}$. Then $0.2 \mathrm{~g}$ of LI-GO was ultrasonicated for $1 \mathrm{~h}$ ahead and was dropped at a rate of $10 \mathrm{~mL} \mathrm{~min}{ }^{-1}$. The mixture was heated to $60{ }^{\circ} \mathrm{C}$ and quickly dropped into ammonia to adjust the $\mathrm{pH}$ of the solution to 11.0. The solution was stirred continuously for $2 \mathrm{~h}$ at $60{ }^{\circ} \mathrm{C}$. The obtained product was magnetically separated and washed to neutral with distilled water. Finally it was dried under vacuum at $60{ }^{\circ} \mathrm{C}$, and the ground product is referred to as LIMGO. MGO was also prepared using similar steps, only LI-GO was replaced with GO.

\subsection{Characterization of LI-MGO}

${ }^{1} \mathrm{H}$ NMR spectra of LI were obtained using an AV600 high resolution nuclear magnetic resonance spectrometer (Bruker, Germany). Transmission electron microscopy (TEM) images of MGO and LI-MGO were recorded using an H-600 electron microscope (Hitachi, Japan). Fourier transform infrared (FT-IR) spectra were obtained using a Nicolet iS10 FT-IR spectrophotometer (Thermo Fisher Scientific, USA). Wide-angle $\left(5-70^{\circ}\right.$, $40 \mathrm{kV} / 30 \mathrm{~mA}$ ) powder X-ray diffraction (XRD) measurements were carried out using a D2 PHASER X-ray diffractometer (Bruker, Germany). The specific surface area and gas adsorption 
isotherms of the sample were measured using $\mathrm{N}_{2}$ physisorption measurements on an ASAP 2020C (Micromeritics, USA). Zeta potentials were measured on a Zetasizer Nano Series (Malvern, Britain).

\subsection{Adsorption experiments}

OIV and GR were chosen as the model of anionic dyes for dye adsorption studies, while AO and CV were chosen as the model of cationic dyes. The chemical structures of the four dyes are shown in Fig. 1. The adsorption processes for the dyes (initial concentration: $40 \mathrm{mg} \mathrm{L}^{-1}$ ) onto MGO and LI-MGO were carried out at the optimum $\mathrm{pH}$ and at different temperatures $(4,25$, and $45{ }^{\circ} \mathrm{C}$ ) in aqueous media. A sample of $0.01 \mathrm{~g}$ of MGO or LI-MGO was added to a conical flask with $25 \mathrm{~mL}$ of dye solution, and the mixture was shaken in a shaker for $12 \mathrm{~h}$. Then the mixture was separated using a magnet and the final concentration of OIV, GR, AO and CV was determined using a UV-Vis spectrophotometer (SPECORD 50 PLUS, Analytikjena, Germany) at $440 \mathrm{~nm}$, $520 \mathrm{~nm}, 490 \mathrm{~nm}$ and $580 \mathrm{~nm}$, respectively. Similarly, the kinetics of adsorption were also measured at different dye concentrations (GR and AO: 20, 40, 60, 80, 100, and $120 \mathrm{mg} \mathrm{L}^{-1}$, and OIV and CV: 2, 4, 8, 12, 16, 20, 24, and $30 \mathrm{mg} \mathrm{L}^{-1}$ ) at the optimum $\mathrm{pH}$ and at different temperatures $\left(4,25\right.$, and $45{ }^{\circ} \mathrm{C}$ ). The adsorption capacities for dyes adsorbed onto MG or LIMGO were determined according the following eqn (1):

$$
q_{\mathrm{t}}=\frac{\left(C_{0}-C_{\mathrm{t}}\right) \times V}{m}
$$

where $C_{0}$ and $C_{\mathrm{t}}$ are the initial and temporary concentrations of the dye $\left(\mathrm{mg} \mathrm{L}^{-1}\right)$, respectively, and $m$ is the weight of the adsorbent (g).

The effect of $\mathrm{pH}$ on the adsorption performance was measured over the $\mathrm{pH}$ range of $2-10$ at $25^{\circ} \mathrm{C}$. The desired $\mathrm{pH}$ of

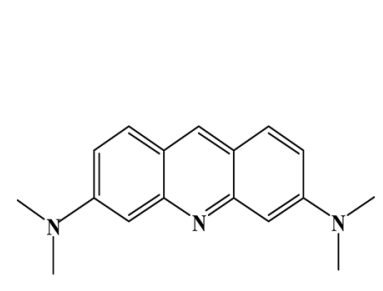

acridine orange

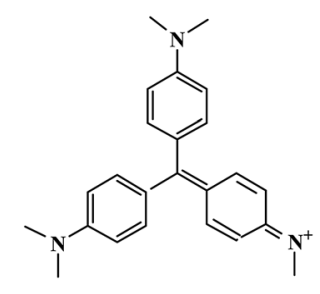

crystal violet<smiles>O=S(=O)([O-])c1cc(O)c(N=Nc2c(O)ccc3ccccc23)c2ccccc12</smiles>

glenn black $\mathrm{R}$ the solution was adjusted by adding Britton-Robinson buffer solution.

\section{Results and discussion}

\subsection{Preparation and characterization of LI-MGO}

Fig. 2 shows a ${ }^{1} \mathrm{H}$ NMR spectrum of 1-amine-3-methyl imidazole chloride. The $\mathrm{H}$ atoms annotated in the chemical structure of 1amine-3-methyl imidazole chloride can be found in Fig. 2. This shows that 1-amine-3-methyl imidazole chloride was synthesized successfully. The synthesis steps of 1-amine-3-methyl imidazole chloride-functionalized MGO are shown in Fig. 3. The synthesis steps of 1-amine-3-methyl imidazole chloride-functionalized MGO are divided into two stages. Firstly, because the surface of graphene oxide contains a large number of carboxyl groups, the carboxyl groups on the surface of graphene oxide reacted with dichloro-sulfoxide to produce acyl chloride groups, which then reacted with the 1-amino-3-methyl imidazole chloride ionic liquid that was synthesized to produce 1-amine-3-methyl imidazole chloride-functionalized GO. In the second step, $\mathrm{Fe}^{3+}$ and $\mathrm{Fe}^{2+}$ were used as ion sources and 1-amine-3-methyl imidazole chloride-functionalized MGO was synthesized through chemical co-precipitation over the pH range of 11-12.

TEM images of MGO and LI-MGO are presented in Fig. 4. The TEM image of MGO shows that the $\mathrm{Fe}_{3} \mathrm{O}_{4}$ nanoparticle distribution is uniform and that they have an average particle size of $10 \mathrm{~nm}$ (Fig. 4a). Fig. 4b reveals that the $\mathrm{Fe}_{3} \mathrm{O}_{4}$ nanoparticles on LI-MGO are larger compared to those on MGO and are present in a layer on the surface of GO. This phenomenon is due to magnetic attraction and the huge nanoparticle surface energy (100 dyn $\mathrm{cm}^{-1}$ ) of the $\mathrm{Fe}_{3} \mathrm{O}_{4}$ nanoparticles, so the $\mathrm{Fe}_{3} \mathrm{O}_{4}$ nanoparticles easily undergo particle agglomeration during the coprecipitation process of LI-GO with $\mathrm{Fe}^{2+}$ and $\mathrm{Fe}^{3+}$. After GO was functionalized with 1-amino-3-methyl imidazole chloride ionic liquid, it can be seen clearly that LI-MGO has a much rougher surface than MGO. The TEM images show that LI-MGO was fabricated successfully.

Fig. 5 shows FT-IR spectra of LI, MGO and LI-MGO. The peak shown by MGO and LI-MGO at $3440 \mathrm{~cm}^{-1}$ corresponds to the

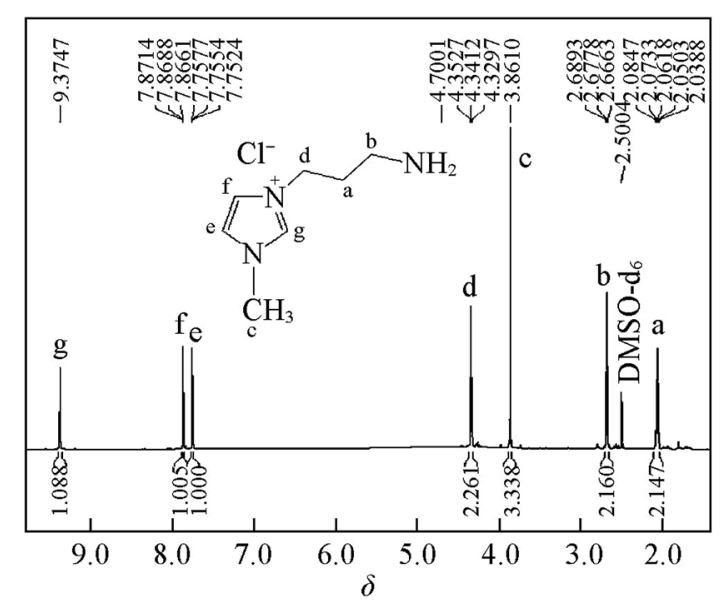

Fig. $2{ }^{1} \mathrm{H}$ NMR spectrum of 1-amine-3-methyl imidazole chloride.

Fig. 1 Chemical structure of dyes. 
<smiles>CN1C=CN(CCCNCCCCl)C1</smiles>
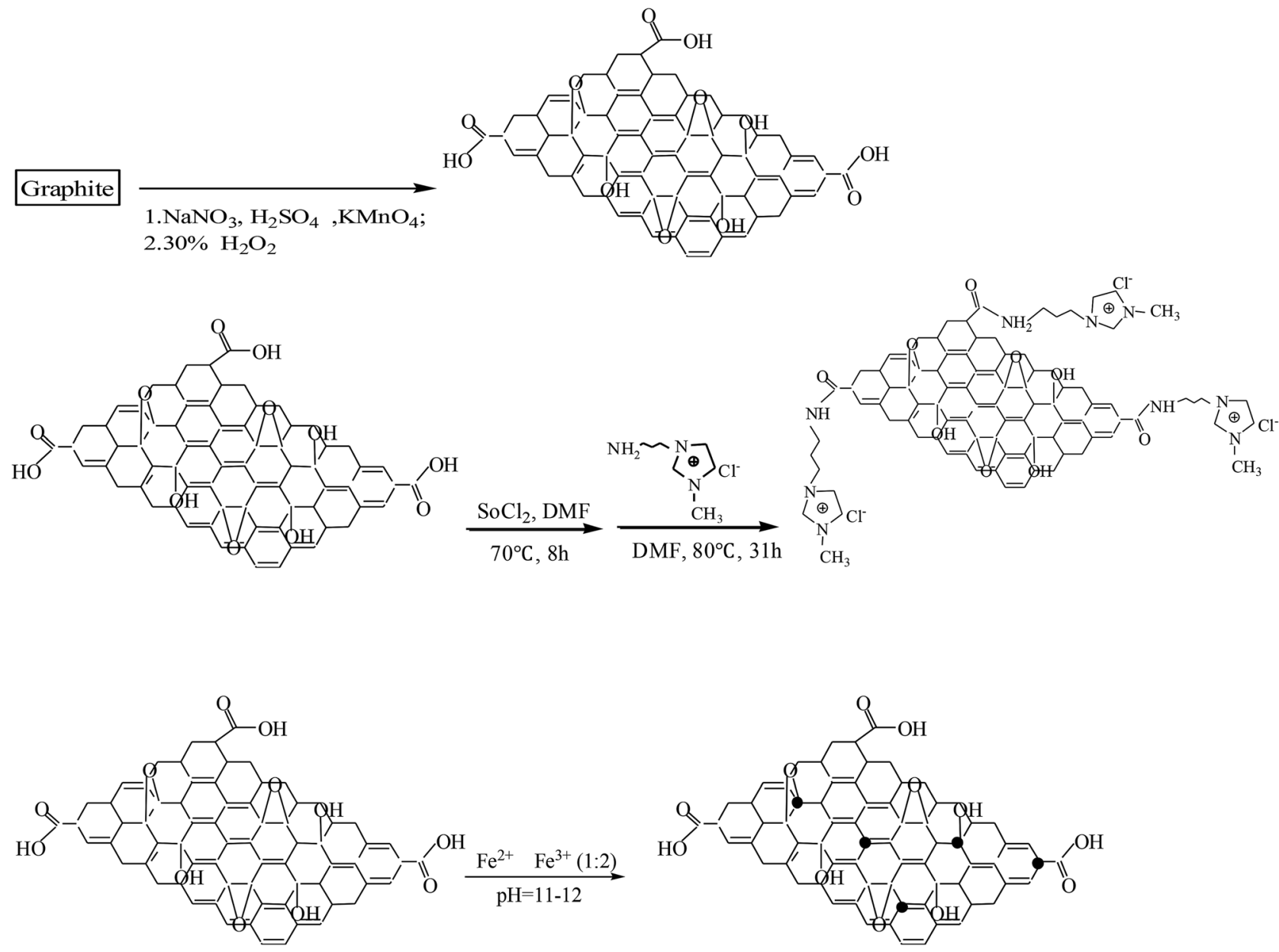

MGO

- $\mathrm{Fe}_{3} \mathrm{O}_{4}$
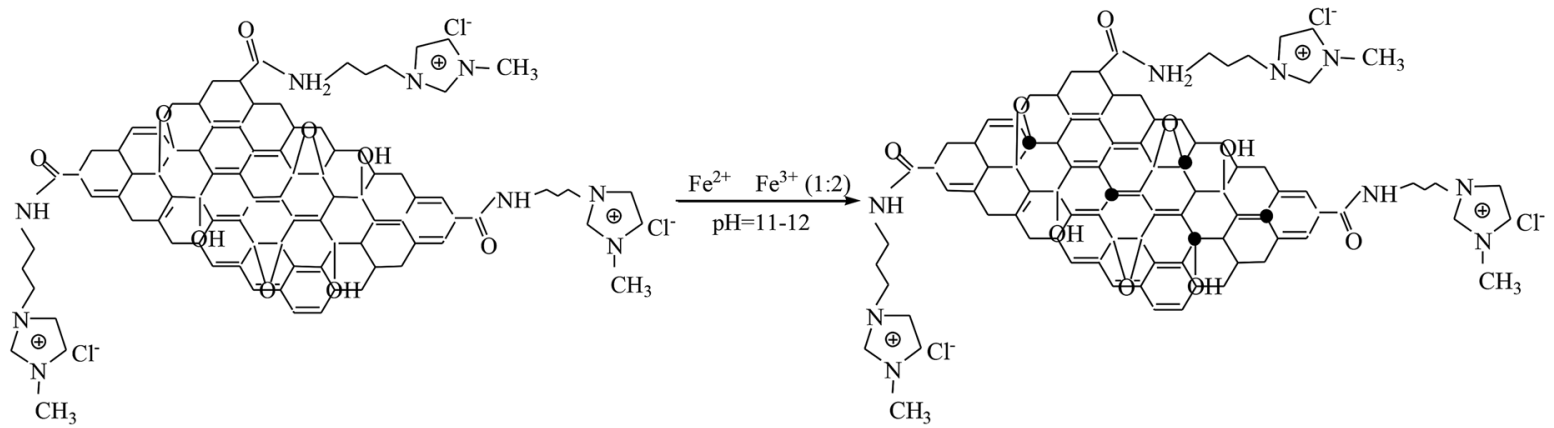

LI-MGO

- $\mathrm{Fe}_{3} \mathrm{O}_{4}$

Fig. 3 Synthesis process of LI-MGO.

characteristic peak of the $\mathrm{O}-\mathrm{H}$ stretching vibration, and the peak at $1690 \mathrm{~cm}^{-1}$ corresponds to $\mathrm{C}=\mathrm{O}$ stretching vibrations of the - $\mathrm{COOH}$ groups. In the FTIR pattern of MGO, a strong adsorption band at $591 \mathrm{~cm}^{-1}$ was observed which was assigned to $\mathrm{Fe}-\mathrm{O}$ vibrations $;^{43}$ the characteristic peak from $\mathrm{Fe}-\mathrm{O}$ vibration was also found in the FTIR pattern of LI-MGO. This revealed that $\mathrm{Fe}_{3} \mathrm{O}_{4}$ nanoparticles were effectively decorated on the surface of the GO layers. It is found that absorption bands at $1170 \mathrm{~cm}^{-1}$ and 1460 

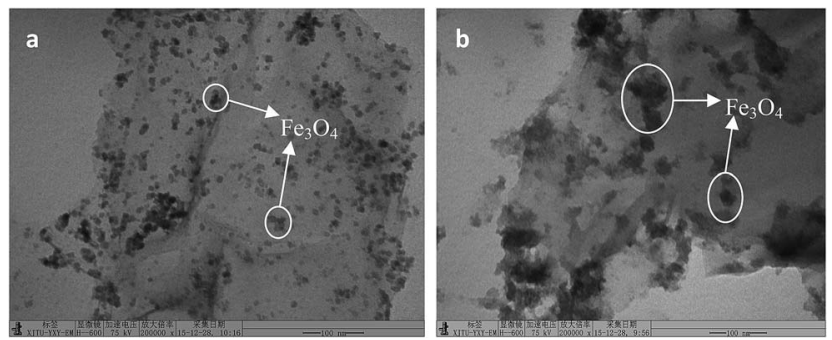

Fig. 4 TEM images of MGO (a) and LI-MGO (b).

$\mathrm{cm}^{-1}$ both emerged in the FT-IR spectra of LI-MGO and LI, which were attributed to $\mathrm{C}-\mathrm{N}$ and $\mathrm{C}=\mathrm{C}$ stretching vibrations, respectively. This indicated that LI has been added onto the MGO sheets.

In order to further study the chemical compositions of LIMGO, GO, MGO and LI-MGO, they were analyzed using XRD as shown in Fig. 6. From Fig. 6a, a strong peak is shown at $11.43^{\circ}$ that resulted from the (002) plane of GO, and a weak wide peak is shown at $21.62^{\circ}$, which is due to the presence of abundant oxygen-containing functional groups on GO and is similar to the reported value for graphite oxide. ${ }^{44}$ As shown in Fig. $6 \mathrm{~b}$ and c, six characteristic diffraction peaks appear at $2 \theta$ values of $30.2^{\circ}, 35.6^{\circ}$, $43.3^{\circ}, 53.7^{\circ}, 57.1^{\circ}$ and $62.8^{\circ}$ in the XRD patterns of MGO and LIMGO, which correspond to the (220), (311), (400), (422), (511) and (440) crystal planes of $\mathrm{Fe}_{3} \mathrm{O}_{4}$, respectively (JCPDS card: 019-0629). The diffraction peaks from $\mathrm{Fe}_{3} \mathrm{O}_{4}$ in the XRD pattern of LI-MGO are stronger than those in the pattern of MGO, but the diffraction peaks from GO were not found in the diffraction patterns of MGO and LI-MGO. The Wang ${ }^{45}$ group also found the peaks from GO missing, and they attributed this phenomenon to two possible reasons. Firstly, as graphene oxide sheet layer aggregation is reduced due to the presence of magnetite, more single layer graphene oxide appears, so in the diffraction pattern the carbon diffraction peak appears as weak. The second reason is that the strong diffraction peak signals from iron oxide weaken the diffraction signal from carbon.

In addition, the specific surface areas of MGO and LI-MGO were examined using $\mathrm{N}_{2}$ physisorption at $-196{ }^{\circ} \mathrm{C}$. Representative $\mathrm{N}_{2}$ adsorption/desorption isotherms for such samples are shown in Fig. 7. Obviously, the isotherms for MGO and LI-MGO

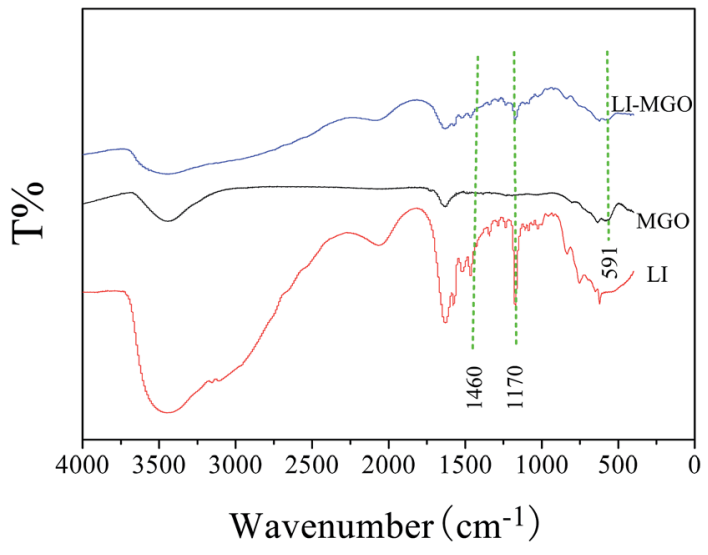

Fig. 5 FTIR spectra of LI, MGO and LI-MGO.

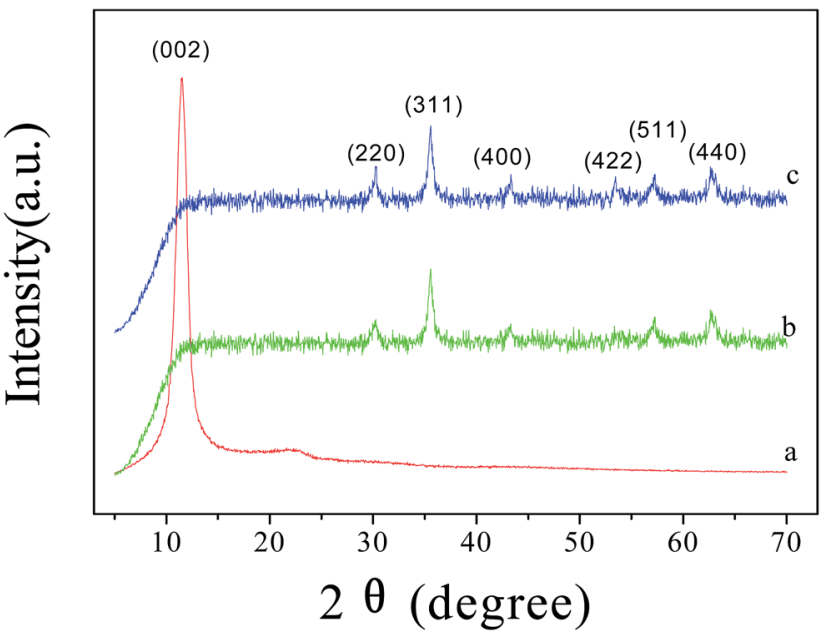

Fig. 6 XRD patterns of GO (a), MGO (b) and LI-MGO (c).

displayed similar features to a type IV isotherm, according to the IUPAC classification. The BET surface area and BJH cumulative pore volume of MGO were measured to be $64.20 \mathrm{~m}^{2} \mathrm{~g}^{-1}$ and $0.2492 \mathrm{~cm}^{3} \mathrm{~g}^{-1}$, respectively. The BET surface area and BJH cumulative pore volume of LI-MGO were measured to be 110.3 $\mathrm{m}^{2} \mathrm{~g}^{-1}$ and $0.2848 \mathrm{~cm}^{3} \mathrm{~g}^{-1}$, respectively. The BET surface area of LI-MGO is larger than MGO due to the surface of LI-MGO being rougher than MGO, after MGO was modified using LI, which is also seen in the TEM images for MGO and LI-MGO (Fig. 4).

\subsection{Effect of $\mathrm{pH}$ on the adsorption capacity}

$\mathrm{pH}$ is one of the important factors that affect adsorption performance. The effect of $\mathrm{pH}$ on the adsorption capacity for the four dyes is shown in Fig. 8. As illustrated in Fig. 8a, the adsorption capacity for GR on MGO and LI-MGO increases over the $\mathrm{pH}$ range from 2.0 to 3.0, while the adsorption capacity for GR on MGO decreases over the $\mathrm{pH}$ range from 3.0 to 7.0. However,

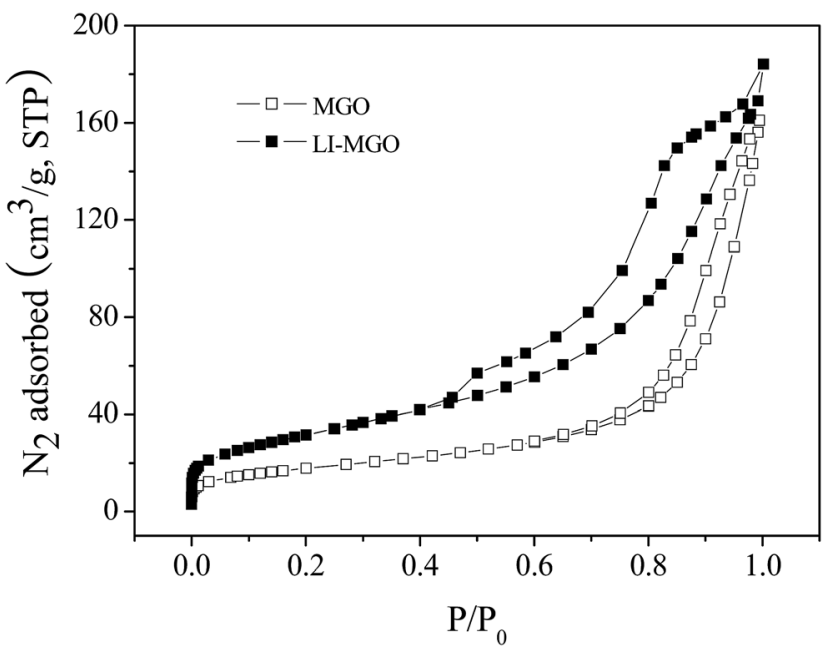

Fig. 7 Nitrogen adsorption-desorption isotherms for MGO and LIMGO. 


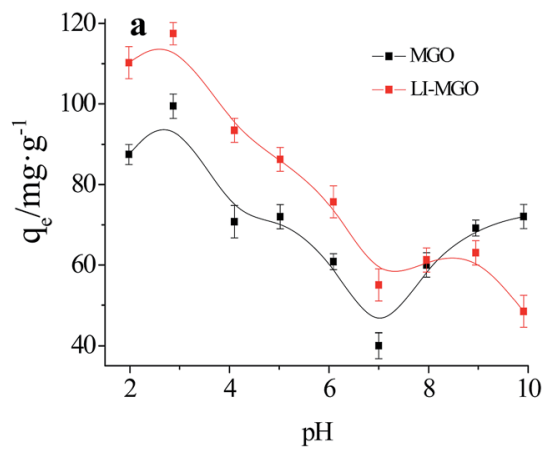

GR

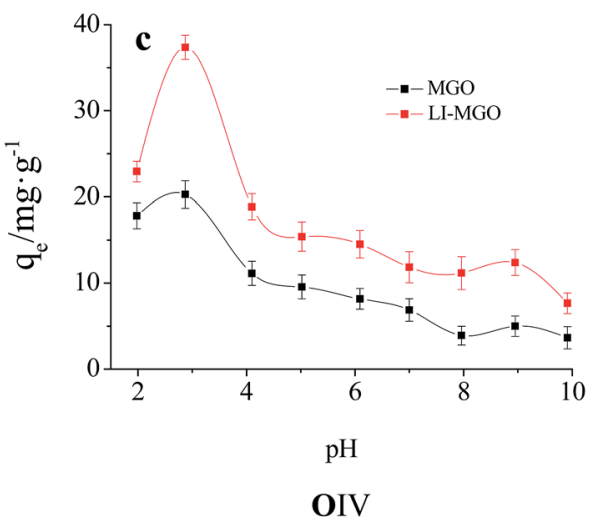

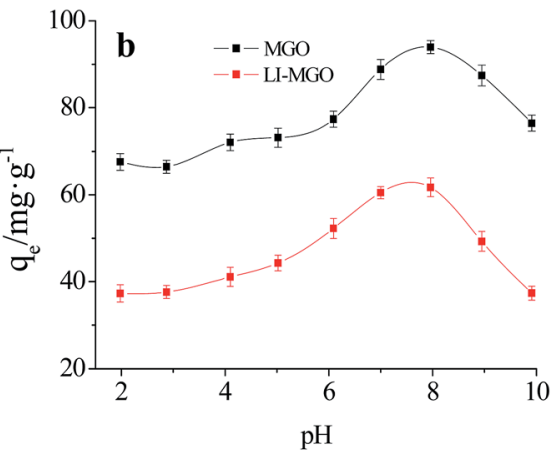

AO

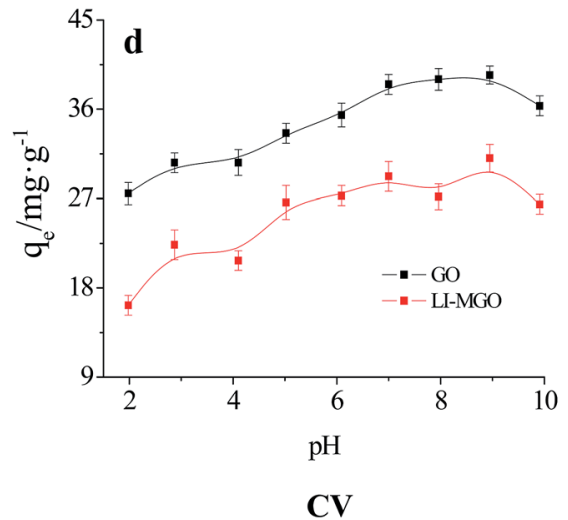

Fig. 8 Effect of pH values on the adsorption capacities of MGO and LI-MGO: (a) GR; (b) AO; (c) OIV; and (d) CV.

when the pH is greater than 7.0, the adsorption capacity for GR on MGO increases gradually. The adsorption capacity for GR on LIMGO decreases over the $\mathrm{pH}$ range from 3.0 to 10.0. The adsorption capacities for GR on MGO and LI-MGO both reach maximum values when the $\mathrm{pH}$ is 3.0. Fig. 8c shows that the adsorption capacity for OIV on MGO and LI-MGO is relatively lower at a low $\mathrm{pH}$, such as $\mathrm{pH}$ 2.0, and the adsorption capacities for OIV on MGO and LI-MGO both reach a maximum at $\mathrm{pH}$ 3.0; then the adsorption capacity for OIV on MGO and LI-MGO gradually decreases with an increase in $\mathrm{pH}$. As shown in Fig. $8 \mathrm{~b}$ and $\mathrm{d}$, the adsorption capacity for $\mathrm{AO}$ and $\mathrm{CV}$ increases along with an increase in $\mathrm{pH}$. The adsorption capacity for $\mathrm{AO}$ reaches a maximum at $\mathrm{pH}$ 8.0, while the adsorption capacity for $\mathrm{CV}$ reaches a maximum at $\mathrm{pH}$ 9.0. Based on the experimental results, the most favorable $\mathrm{pH}$ values for GR, OIV, AO and CV adsorption on MGO and LI-MGO are around 3.0, 3.0, 8.0, and 9.0, respectively.

The effect of $\mathrm{pH}$ on adsorption capacity is not only related to the surface charge of the adsorbent, but also to the dissociated form of the dye. The zeta potentials of MGO and LI-MGO at different $\mathrm{pH}$ values are shown in Fig. 9. The zero potential points $\left(\mathrm{pH}_{\mathrm{pzc}}\right)$ of MGO and LI-MGO are 2.4 and 2.9, respectively (Fig. 9). When the $\mathrm{pH}<2.4$, the surface of MGO is positively charged, while when the $\mathrm{pH}>2.4$, the surface of MGO is negatively charged. When the $\mathrm{pH}<2.9$, the surface of LI-MGO is positively charged, while when the $\mathrm{pH}>2.9$, the surface of LI-MGO is negatively charged. The four dyes include two anionic dyes, GR and OIV, and two cationic dyes, AO and CV. GR and OIV can exist as anions when the $\mathrm{pH}>\mathrm{p} K_{\mathrm{a}}$; the negative charge on the surface of MGO and LI-MGO at around $\mathrm{pH} 3.0$ is lower and close to zero, so the electrostatic interaction between GR and OIV and MGO and LI-MGO is strongest, and the adsorption capacity is maximal. AO and $\mathrm{CV}$ can existed as cations when the $\mathrm{pH}>\mathrm{p} K_{\mathrm{a}}$, and the negative charge on the surface of MGO and LI-MGO at around pH 8.0 is greatest. So the electrostatic interaction between $\mathrm{AO}$ and $\mathrm{CV}$ and MGO and LI-MGO is strongest, and the adsorption capacity reaches the maximum. In addition, the surface negative charge of

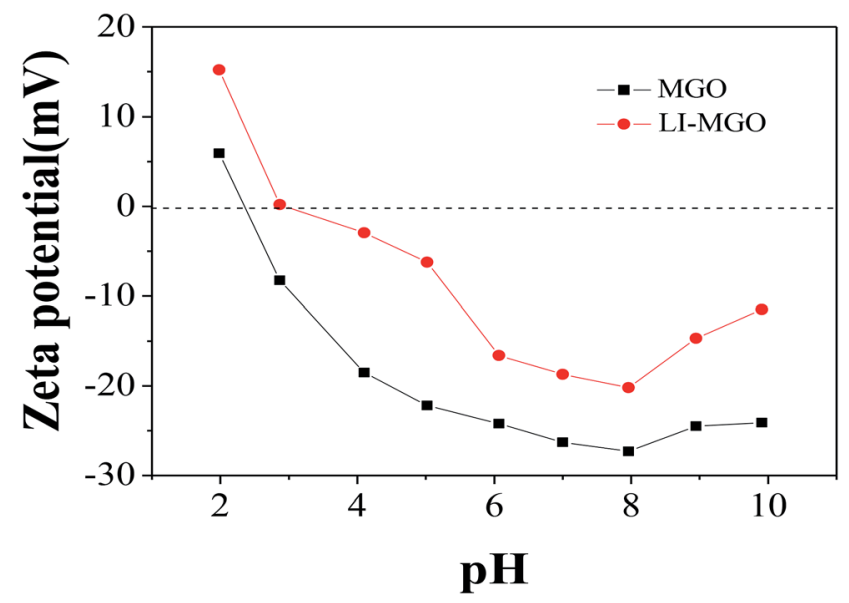

Fig. 9 Zeta potentials of MGO and LI-MGO at different $\mathrm{pH}$ values. 


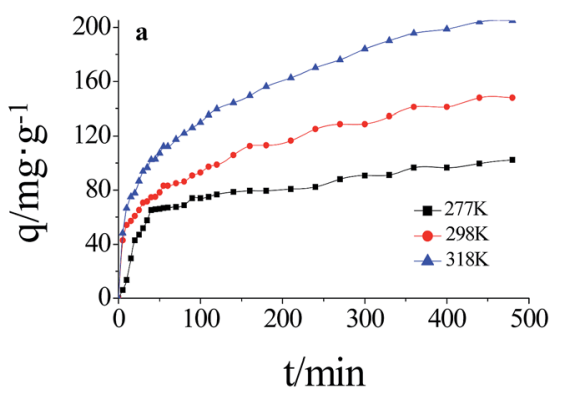

GR

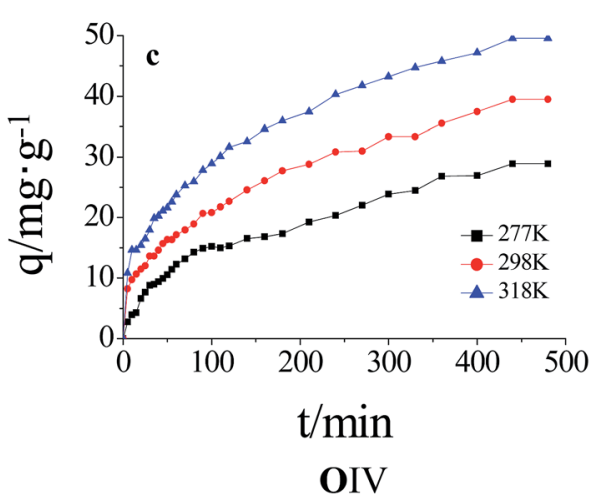

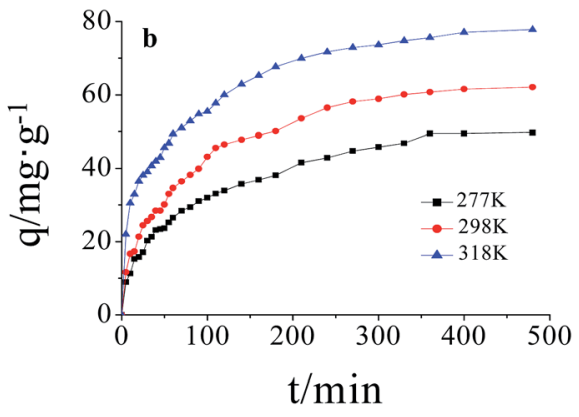

AO

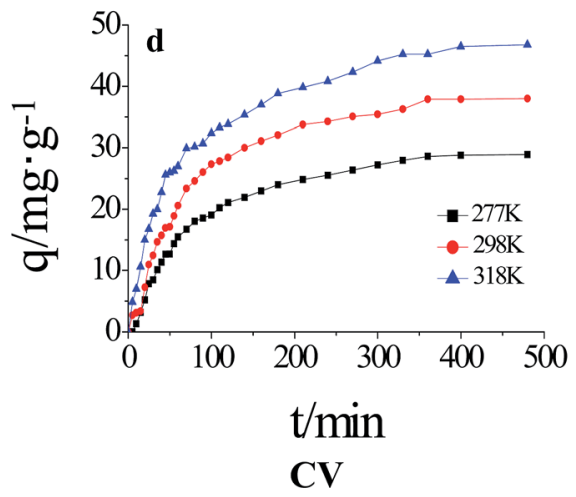

Fig. 10 Kinetics of dye adsorption on LI-MGO at $277 \mathrm{~K}, 298 \mathrm{~K}$ and $318 \mathrm{~K}$ : (a) GR; (b) AO; (c) OIV; (d) CV.

MGO is stronger than LI-MGO at different pH values (Fig. 9). This also can explain why the adsorption capacity for anionic dyes on LI-MGO is greater than on MGO and why the adsorption capacity for cationic dyes on MGO is greater than on LI-MGO.

\subsection{Adsorption kinetics}

Fig. 10 describes the adsorption capacity for four dyes on LIMGO versus time at $277 \mathrm{~K}, 298 \mathrm{~K}$ and $318 \mathrm{~K}$. The four dyes are adsorbed rapidly over the first $100 \mathrm{~min}$, and thereafter they proceed at a slow rate and finally achieve equilibrium at $300 \mathrm{~min}$. The adsorption capacity at equilibrium for the four dyes on LI-MGO increases as the temperature increases.
In order to study the mechanism of adsorption, the kinetic data were fitted using a pseudo-first-order kinetic model, ${ }^{\mathbf{4 6}}$ pseudo-second-order kinetic model $^{47}$ and intraparticle diffusion model; ${ }^{\mathbf{4}}$ the three models are expressed using the following equations:

$$
\begin{aligned}
\frac{t}{q_{t}} & =\frac{1}{k_{2} q_{\mathrm{e}}^{2}}+\frac{t}{q_{\mathrm{e}}} \\
q_{t} & =k_{\mathrm{int}} t^{1 / 2}
\end{aligned}
$$$$
\log \left(q_{\mathrm{e}}-q_{t}\right)=\log q_{\mathrm{e}}-k_{1} \frac{t}{2.303}
$$

\begin{tabular}{|c|c|c|c|c|c|c|c|c|c|c|}
\hline Dye & $T / \mathrm{K}$ & $q_{\text {eqex }} / \mathrm{mg} \mathrm{g}^{-1}$ & $k_{1}\left(\times 10 \min ^{-1}\right)$ & $q_{\mathrm{e}} / \mathrm{mg} \mathrm{g}^{-1}$ & $R^{2}$ & $k_{2}\left(\times 10^{2} \mathrm{~g} \mathrm{mg}^{-1} \min ^{-1}\right)$ & $q_{\mathrm{e}} / \mathrm{mg} \mathrm{g}^{-1}$ & $R^{2}$ & $k_{\text {int }}\left(\mathrm{mg} \mathrm{g}^{-1} \min ^{-1 / 2}\right)$ & $R^{2}$ \\
\hline & 298 & 147.8 & 0.0613 & 100.23 & 0.929 & 0.01320 & 156.3 & 0.986 & 5.647 & 0.952 \\
\hline & 318 & 204.9 & 0.0627 & 143.22 & 0.936 & 0.00897 & 217.9 & 0.986 & 8.159 & 0.958 \\
\hline & 277 & 28.90 & 0.0497 & 24.39 & 0.909 & 0.02790 & 33.3 & 0.962 & 1.318 & 0.987 \\
\hline OIV & 277 & 49.74 & 0.0778 & 39.40 & 0.957 & 0.03157 & 54.44 & 0.987 & 2.741 & 0.978 \\
\hline \multirow[t]{3}{*}{$\mathrm{AO}$} & 298 & 62.08 & 0.0937 & 50.45 & 0.974 & 0.02720 & 68.63 & 0.992 & 3.763 & 0.979 \\
\hline & 318 & 77.81 & 0.0942 & 54.14 & 0.953 & 0.03449 & 81.97 & 0.994 & 4.196 & 0.945 \\
\hline & 277 & 28.84 & 0.0814 & 26.01 & 0.986 & 0.03523 & 34.78 & 0.998 & 2.789 & 0.989 \\
\hline \multirow[t]{2}{*}{$\mathrm{CV}$} & 298 & 37.88 & 0.0947 & 32.70 & 0.978 & 0.03147 & 44.68 & 0.997 & 3.616 & 0.976 \\
\hline & 318 & 46.46 & 0.0859 & 36.10 & 0.972 & 0.03419 & 51.89 & 0.996 & 3.894 & 0.967 \\
\hline
\end{tabular}

Table 1 Kinetic parameters for the adsorption of dyes onto LI-MGO at $277 \mathrm{~K}, 298 \mathrm{~K}$ and $318 \mathrm{~K}$ 


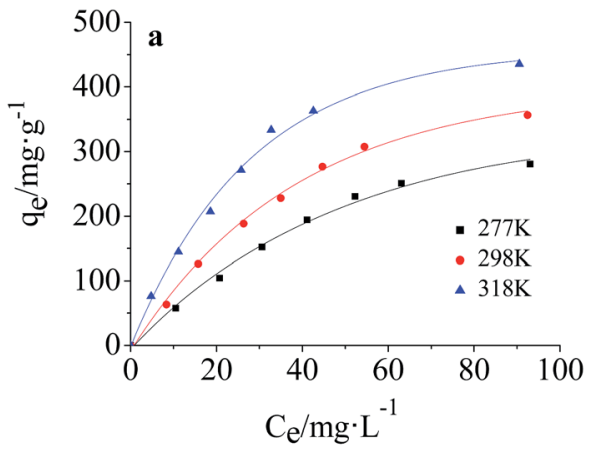

GR

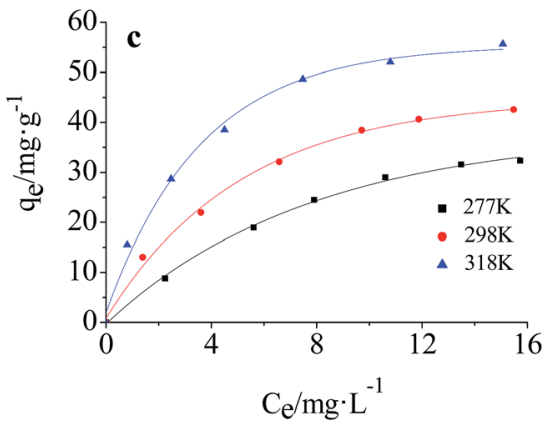

OIV

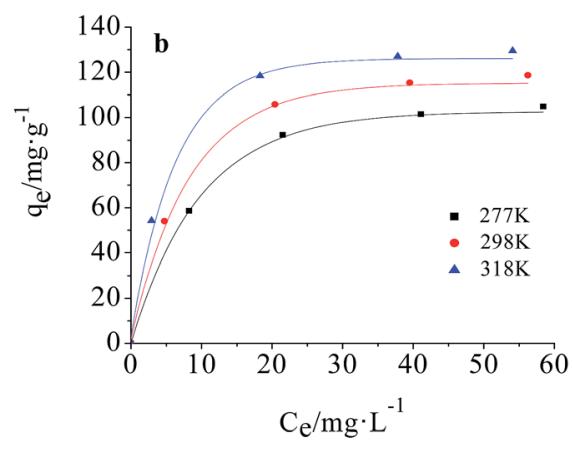

$\mathrm{AO}$

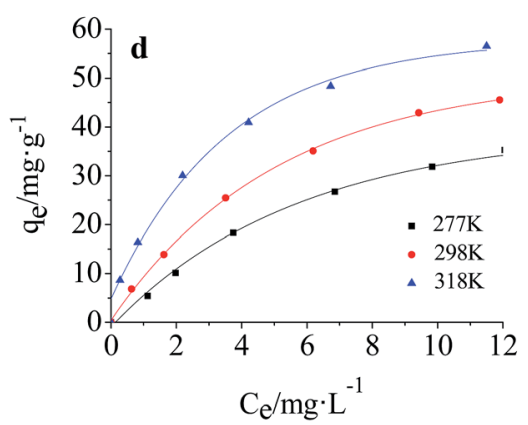

CV

Fig. 11 Adsorption isotherms for dye adsorption on LI-MGO at $277 \mathrm{~K}, 298 \mathrm{~K}$ and $318 \mathrm{~K}$ : (a) GR; (b) AO; (c) OIV; (d) CV.

where $q_{\mathrm{e}}\left(\mathrm{mg} \mathrm{g}^{-1}\right)$ is the equilibrium adsorption capacity, $q_{t}(\mathrm{mg}$ $\mathrm{g}^{-1}$ ) is the amount adsorbed at time $t, k_{1}$ is the equilibrium rate constant of pseudo-first-order adsorption $\left(\mathrm{min}^{-1}\right), k_{2}\left(\mathrm{~g} \mathrm{mg}^{-1}\right.$ $\min ^{-1}$ ) is the rate constant of pseudo-second-order adsorption, and $k_{\text {int }}\left(\mathrm{mg} \mathrm{g}^{-1} \mathrm{~min}^{-1 / 2}\right)$ is the rate constant for intraparticle diffusion adsorption.

$k_{1}$ and $q_{\mathrm{e}}$ were obtained from the slope and intercept of $\log \left(q_{\mathrm{e}}-q_{t}\right)$ versus $t, k_{2}$ and $q_{\mathrm{e}}$ were obtained from the slope and intercept of $t / q_{t}$ versus $t$, and $k_{\text {int }}$ can be calculated from the slope of $q_{t}$ versus $t_{0.5}$.

The kinetic parameters obtained from the pseudo-first-order equation, pseudo-second-order equation and intraparticle diffusion equation are listed in Table 1 . The $R^{2}$ values and the large discrepancy between the experimental and calculated $q_{\mathrm{e}}$ indicates that the adsorption of the four dyes does not follow the pseudo first-order kinetic model or intraparticle diffusion model. As a result, the adsorption of the four dyes onto LI-MGO is in accordance with the pseudo second-order kinetic model, in which the adsorption process is the rate-limiting step, involving the surface.

\subsection{Adsorption isotherms}

The adsorption isotherms for OIV, GR, AO and CV on LI-MGO at $277 \mathrm{~K}, 298 \mathrm{~K}$ and $318 \mathrm{~K}$ are shown in Fig. 11. The adsorption capacity of LI-MGO reaches a maximum with an increase in initial dye concentration, as shown in Fig. 11.

The study of adsorption equilibrium can be a good assessment of adsorption capacity. The adsorption data for the dyes on LI-MGO were fitted using two classical adsorption models - the Langmuir and Freundlich models. The Langmuir equation and Freundlich equation can be expressed in linear form using eqn (5) and (6), respectively.

$$
\begin{gathered}
\frac{C_{\mathrm{e}}}{q_{\mathrm{e}}}=\frac{1}{q_{\mathrm{m}} K_{\mathrm{L}}}+\frac{C_{\mathrm{e}}}{q_{\mathrm{m}}} \\
\log q_{\mathrm{e}}=\log K_{\mathrm{F}}+\left[\frac{1}{n}\right] \log C_{\mathrm{e}}
\end{gathered}
$$

where $q_{\mathrm{e}}$ and $q_{\mathrm{m}}\left(\mathrm{mg} \mathrm{g}^{-1}\right)$ are the dye adsorption capacity at equilibrium and the maximum adsorption capacity, respectively, $K_{\mathrm{L}}\left(\mathrm{L} \mathrm{mg}{ }^{-1}\right)$ is the Langmuir constant, $K_{\mathrm{F}}$

Table 2 Adsorption isotherm parameters for the adsorption of dyes

\begin{tabular}{|c|c|c|c|c|c|c|c|}
\hline \multirow[b]{2}{*}{ Dye } & \multirow[b]{2}{*}{$T / \mathrm{K}$} & \multicolumn{3}{|c|}{ Langmuir equation } & \multicolumn{3}{|c|}{ Freundlich equation } \\
\hline & & $q_{\mathrm{m}} / \mathrm{mg} \mathrm{g}^{-1}$ & $K_{\mathrm{L}} / \mathrm{L} \mathrm{mg}^{-1}$ & $R$ & $K_{\mathrm{F}} / \mathrm{mg} \mathrm{g}^{-1}$ & $n$ & $R$ \\
\hline \multirow[t]{4}{*}{ GR } & 277 & 578.03 & 0.01137 & 0.9778 & 9.9136 & 1.2835 & 0.9709 \\
\hline & 298 & 588.24 & 0.01809 & 0.9907 & 15.541 & 1.3600 & 0.9792 \\
\hline & 318 & 606.06 & 0.03080 & 0.9921 & 33.204 & 1.6273 & 0.9713 \\
\hline & 277 & 55.52 & 0.09538 & 0.9934 & 5.3265 & 1.4269 & 0.9902 \\
\hline \multirow[t]{3}{*}{ OIV } & 298 & 57.37 & 0.1947 & 0.9969 & 11.385 & 1.9495 & 0.9925 \\
\hline & 318 & 65.65 & 0.3446 & 0.9988 & 19.136 & 2.5103 & 0.9697 \\
\hline & 277 & 119.33 & 0.1328 & 0.9990 & 33.059 & 3.3436 & 0.9547 \\
\hline \multirow[t]{3}{*}{$\mathrm{AO}$} & 298 & 132.80 & 0.1615 & 0.9994 & 34.103 & 3.0276 & 0.9646 \\
\hline & 318 & 140.06 & 0.2449 & 0.9997 & 41.006 & 3.2066 & 0.9653 \\
\hline & 277 & 65.96 & 0.09632 & 0.9958 & 6.2395 & 1.3786 & 0.9942 \\
\hline \multirow[t]{2}{*}{$\mathrm{CV}$} & 298 & 69.44 & 0.1642 & 0.9983 & 9.9234 & 1.5185 & 0.9938 \\
\hline & 318 & 70.03 & 0.3485 & 0.9994 & 18.001 & 1.9319 & 0.9928 \\
\hline
\end{tabular}
onto LI-MGO at $277 \mathrm{~K}, 298 \mathrm{~K}$ and $318 \mathrm{~K}$ 
Table 3 Thermodynamic parameters for the adsorption of four dyes onto LI-MGO

\begin{tabular}{lllll}
\hline Dye & $T / \mathrm{K}$ & $\begin{array}{l}\Delta G \\
\left(\mathrm{~kJ} \mathrm{~mol}^{-1}\right)\end{array}$ & $\begin{array}{l}\Delta H \\
(\mathrm{~kJ} \mathrm{~mol})\end{array}$ & $\begin{array}{l}\Delta S \\
\left(\mathrm{~J} \mathrm{~mol}^{-1} \mathrm{~K}^{-1}\right)\end{array}$ \\
\hline $\mathrm{GR}$ & 277 & -3.685 & 17.12 & 74.98 \\
& 298 & -5.148 & & \\
& 318 & -6.771 & & \\
& 277 & -3.354 & & \\
OIV & 298 & -4.078 & 7.287 & 38.33 \\
& 318 & -4.935 & & \\
$\mathrm{AO}$ & 277 & -1.959 & & \\
& 298 & -3.046 & 12.88 & \\
& 318 & -4.157 & & \\
$\mathrm{CV}$ & 277 & -2.469 & & \\
& 298 & -3.323 & 0.9550 & \\
& 318 & -4.209 & & \\
\hline
\end{tabular}

$\left(\mathrm{mg} \mathrm{mg}^{-1}\right.$ ) is related to the adsorption capacity of the adsorbent, and $1 / n$ is a constant that is related to adsorption intensity.

As shown in Table 2, the $R$ value from the Langmuir model is much larger than that from the Freundlich isotherm, and the adsorption capacity calculated from the Langmuir isotherm is closer to the experimental $q_{\mathrm{e}}$. Hence, the Langmuir model is more appropriate than the Freundlich model for describing the adsorption behavior of OIV, GR, AO and CV onto LI-MGO. This implies monolayer coverage of OIV, GR, AO and CV on LI-MGO and also a homogeneous distribution of active sites on the adsorbent, as the Langmuir equation assumes that the surface is homogeneous.

\subsection{Adsorption thermodynamics}

Thermodynamic parameter changes, such as in the standard free energy $\left(\Delta G^{\circ} / \mathrm{kJ} \mathrm{mol}^{-1}\right)$, enthalpy $\left(\Delta H^{\circ} / \mathrm{kJ} \mathrm{mol}^{-1}\right)$ and entropy $\left(\Delta S^{\circ} / \mathrm{J} \mathrm{mol}^{-1} \mathrm{~K}^{-1}\right)$, were calculated using the following equations:

$$
\begin{gathered}
\Delta G^{\circ}=-R T \ln K_{\mathrm{C}} \\
\Delta H^{\circ}=\Delta G^{\circ}+T \Delta S^{\circ} \\
K_{\mathrm{C}}=\frac{q_{\mathrm{e}}}{C_{\mathrm{e}}}
\end{gathered}
$$

where $K_{\mathrm{C}}$ is the equilibrium constant. The van't Hoff equation is written as follows according to a combination of eqn (7), (8) and (9).

$$
\ln K_{\mathrm{C}}=\frac{-\Delta H^{\circ}}{R} \frac{1}{T}+\frac{\Delta S^{\circ}}{R}
$$

$\Delta H^{\circ}$ and $\Delta S^{\circ}$ were calculated from the slope and intercept of a linear plot of $\ln K_{\mathrm{C}}$ versus $1 / T$ (Fig. S3, ESI $\dagger$ ). The values of $\Delta G^{\circ}$, $\Delta H^{\circ}$ and $\Delta S^{\circ}$ are listed in Table 3 . The negative values of $\Delta G^{\circ}$ indicate that adsorption is spontaneous at the studied temperatures. The positive values of $\Delta H^{\circ}$ and $\Delta S^{\circ}$ for the adsorption of the four dyes onto LI-MGO indicate that the adsorption process is endothermic and random, respectively. This also explains why the adsorption capacity at equilibrium for the four dyes on LI-MGO increases as the temperature increases.

\subsection{Adsorption capacity comparison}

A comparison of adsorbents from similar anionic dye studies reported in the literature is displayed in Table 4 . The maximum adsorption capacity of glenn black R on LI-MGO is greater compared to other anionic dyes on absorbents reported in the literature. LI-MGO has superior adsorption efficiency for anionic dyes, which may be ascribed to the surface of MGO

\begin{tabular}{|c|c|c|c|}
\hline $\mathrm{Fe}_{3} \mathrm{O}_{4} @ n \mathrm{SiO}_{2} @ m \mathrm{SiO}_{2} @ \mathrm{DHIM}-\mathrm{NH}_{2}$ & Orange II & 142.49 & 49 \\
\hline & Methyl orange & 202.4 & \\
\hline GG- $g$-poly(DMAEMA) gels & Methyl orange & 25.8 & 51 \\
\hline CTAB-modified pumice & Congo red & 27.32 & 52 \\
\hline & Amaranth & 84.04 & \\
\hline & Acid red 18 & 134.69 & \\
\hline PbO-NP-AC & Methyl orange & 333.33 & 55 \\
\hline CMOPP & Congo red & 163 & 56 \\
\hline \multirow[t]{2}{*}{ Amine $/ \mathrm{Fe}_{3} \mathrm{O}_{4}$-resin } & Methyl orange & 101.0 & 57 \\
\hline & Reactive brilliant red K-2BP & 222.2 & \\
\hline & orange IV & 57.37 & \\
\hline
\end{tabular}
having increased positive charge after 1-amine-3-methyl imidazole chloride functionalization.

Table 4 Comparison of the maximum adsorption capacities for anionic dyes of different adsorbents 


\section{Conclusions}

In summary, a novel LI-MGO adsorbent functionalized with 1amine-3-methyl imidazole chloride ionic liquid was successfully prepared through a facile chemical co-precipitation and chemical modification method. LI-MGO exhibited a higher surface area than MGO. In order to research the adsorption properties of LI-MGO, two kinds of anionic dyes, OIV and GR, and two kinds of cationic dyes, $\mathrm{AO}$ and $\mathrm{CV}$, were investigated as model dyes. LI-MGO showed remarkably higher adsorption capacities for the anionic dyes compared with MGO and referenced materials, due to LI-MGO being a surface cationic modified material and electrostatic interactions between LIMGO and the anionic dyes. In addition, the advantages of its rapid separation from water and low cost give LI-MGO a good chance to be applied in the removal of anionic dyes from wastewater.

\section{Conflict of interest}

The authors declare there is no conflict of interest.

\section{Acknowledgements}

This work was supported by the Nation Natural Science Foundation of China (No. 21475104).

\section{References}

1 K. R. Ramakrishna and T. Viraraghavan, Water Sci. Technol., 1997, 36, 189-196.

2 N. R. Khalid, E. Ahmed, Z. Hong, L. Sana and M. Ahmed, Curr. Appl. Phys, 2013, 13, 659-663.

3 D. Stergiopoulos, K. Dermentzis, P. Giannakoudakis and S. Sotiropoulos, Global NEST J., 2014, 16, 499-506.

4 M. F. Abid, M. A. Zablouk and A. M. Abidalameer, Iran. J. Environ. Health Sci. Eng., 2012, 9, 17-25.

5 M. Wawrzkiewicz, Chem. Eng. J., 2013, 217, 414-425.

6 T. Ma, P. R. Chang, P. Zheng, F. Zhao and X. Ma, Chem. Eng. J., 2014, 240, 595-600.

7 N. Öztürk and T. E. Bektas, Fresenius Environ. Bull., 2006, 15, 489-496.

8 W. Hajjaji, R. C. Pullar, J. A. Labrincha and F. Rocha, Appl. Clay Sci., 2016, 126, 197-206.

9 S. Yang, L. Wang, X. Zhang, W. Yang and G. Song, Chem. Eng. J., 2015, 275, 315-321.

10 L. Gao, Q. Li, X. Hu, X. Wang, H. Song, L. Yan and H. Xiao, Appl. Clay Sci., 2016, 126, 299-305.

11 Y. Yu, B. N. Murthy, J. G. Shapter, K. T. Constantopoulos, N. H. Voelcker and A. V. Ellis, J. Hazard. Mater., 2013, 260, 330-338.

12 H. Gao, Y. Sun, J. Zhou, R. Xu and H. Duan, ACS Appl. Mater. Interfaces, 2013, 5, 425-432.

13 M. S. Mauter and M. Elimelech, Environ. Sci. Technol., 2008, 42, 5843-5859.

14 J. Liu, W. Liu, Y. Wang, M. Xu and B. Wang, Appl. Surf. Sci., 2016, 367, 327-334.
15 D. Robati, B. Mirza, M. Rajabi, O. Moradi, I. Tyagi, S. Agarwal and V. K. Gupta, Chem. Eng. J., 2016, 284, 687-697.

16 D. Wang, L. Liu, X. Jiang, J. Yu, X. Chen and X. Chen, Appl. Surf. Sci., 2015, 329, 197-205.

17 S. T. Yang, S. Chen, Y. Chang, A. Cao, Y. Liu and H. Wang, J. Colloid Interface Sci., 2011, 359, 24-29.

18 G. Xie, P. Xi, H. Liu, F. Chen, L. Huang, Y. Shi, et al., J. Mater. Chem., 2012, 22, 1033-1039.

19 V. K. Sharma, T. J. Mcdonald, H. Kim and V. K. Garg, Adv. Colloid Interface Sci., 2015, 225, 229-240.

20 O. Moradi, V. K. Gupta, S. Agarwal, I. Tyagi, M. Asif, et al., J. Ind. Eng. Chem., 2015, 28, 294-301.

21 J. Liu, G. Liu and W. Liu, Chem. Eng. J., 2014, 257, 299-308. 22 D. Wang, L. Liu, X. Jiang, J. Yu and X. Chen, Colloids Surf., A, 2015, 466, 166-173.

23 R. Rajesh, S. S. Iyer, J. Ezhilan, S. S. Kumar and R. Venkatesan, Spectrochim. Acta, Part A, 2016, 166, 49-55.

24 H. Wang, H. Gao, M. Chen, X. Xu, X. Wang, et al., Appl. Surf. Sci., 2016, 360, 840-848.

25 D. Chen, H. Zhang, K. Yang and H. Wang, J. Hazard. Mater., 2016, 310, 179-187.

26 P. N. Diagboya, B. I. Olu-Owolabi, D. Zhou and B. H. Han, Carbon, 2014, 79, 174-182.

27 G. K. Ramesha, A. V. Kumara, H. B. Muralidhara and S. Sampath, J. Colloid Interface Sci., 2011, 361, 270-277.

28 T. Zhou, W. Lu, L. Liu, H. Zhu, Y. Jiao, S. Zhang and R. Han, J. Mol. Liq., 2015, 211, 909-914.

29 C. Namasivayam and M. V. Sureshkumar, J. Appl. Polym. Sci., 2006, 100, 1538-1546.

30 Y. Su, B. Zhao, W. Xiao and R. Han, Environ. Sci. Pollut. Res., 2013, 20, 5558-5568.

31 V. S. Munagapati and D. S. Kim, J. Mol. Liq., 2016, 220, 540-548.

32 K. Li, P. Li, J. Cai, S. Xiao, H. Yang and A. Li, Chemosphere, 2016, 154, 310-318.

33 M. Armand, F. Endres, D. R. Macfarlane, H. Ohno and B. Scrosati, Nat. Mater., 2009, 8, 621-629.

34 N. V. Plechkova and K. R. Seddon, Chem. Soc. Rev., 2008, 37, 123-150.

35 U. Domańska, P. Okuniewska and M. Królikowski, Fluid Phase Equilib., 2016, 423, 109-119.

36 B. Lam, M. Wei, L. Zhu, S. J. Luo, R. Guo, et al., Polymer, 2016, 89, 1-11.

37 K. Moodley, M. Mabaso, I. Bahadur and G. G. Redhi, J. Mol. Liq., 2016, 219, 206-210.

38 B. Lin, H. Shang, F. Chu, Y. Ren, N. Yuan, B. Jia, et al., Electrochim. Acta, 2014, 134, 209-214.

39 Q. Zhou, F. Chen, W. Wu, R. Bu, W. Li and F. Yang, Chem. Eng. J., 2016, 285, 198-206.

40 W. Song, Y. Liu, L. Qian, L. Niu, L. Xiao, et al., Chem. Eng. J., 2016, 287, 482-491.

41 L. X. Gao and J. Yu, Chem. J. Chin. Univ., 2013, 34, 108-114. 42 L. Sun, H. Yu and B. Fugetsu, J. Hazard. Mater., 2012, 203204, 101-110.

43 F. Bianchi, V. Chiesi, F. Casoli, P. Luches, L. Nasi, M. Careri and A. Mangia, J. Chromatogr. A, 2012, 1231, 8-15.

44 P. Bradder, S. K. Ling, S. Wang and S. Liu, J. Chem. Eng. Data, 2011, 56, 138-141. 
45 X. Yang, C. Chen, J. Li, G. Zhao, X. Ren and X. Wang, RSC Adv., 2012, 2, 8821-8826.

46 A. Aluigi, F. Rombaldoni, C. Tonetti and L. Jannoke, J. Hazard. Mater., 2014, 268, 156-165.

47 Z. Chen, J. Zhang, J. Fu, M. Wang, X. Wang, R. Han and Q. Xu, J. Hazard. Mater., 2014, 273, 263-271.

48 S. Wan, F. He, J. Wu, W. Wan, Y. Gu and B. Gao, J. Hazard. Mater., 2016, 314, 32-40.

49 J. Cheng, L. Shi and J. Lu, J. Ind. Eng. Chem., 2016, 36, 206214.

50 H. Li, N. An, G. Liu, J. Li, N. Liu, M. Jia, et al., J. Colloid Interface Sci., 2016, 466, 343-351.

51 J. S. Karthika and B. Vishalakshi, Int. J. Biol. Macromol., 2015, 81, 648-655.
52 H. Shayesteh, A. Rahbar-Kelishami and R. Norouzbeigi, J. Mol. Liq., 2016, 221, 1-11.

53 T. A. Saleh, A. M. Muhammad and S. A. Ali, J. Colloid Interface Sci., 2016, 468, 324-333.

54 Y. R. Zhang, P. Su, J. Huang, Q. R. Wang and B. X. Zhao, Chem. Eng. J., 2015, 262, 313-318.

55 M. Ghaedia, A. M. Ghaedi, B. Mirtamizdoust, S. Agarwal and V. K. Gupta, J. Mol. Liq., 2016, 213, 48-57.

56 V. S. Munagapati and D. S. Kim, J. Mol. Liq., 2016, 220, 540548.

57 W. Song, B. Gao, X. Xu, L. Xing, S. Han, et al., Bioresour. Technol., 2016, 210, 123-130.

58 T. Wang, P. Zhao, N. Lu, H. Chen, et al., Chem. Eng. J., 2016, 295, 403-413. 